\title{
ИТАЛИЯ И ФРАНЦИЯ: КОНФЛИКТ ПО ВОПРОСУ БУДУЩЕГО ЕС*
}

\begin{abstract}
Аннотация. С приходом к власти в Италии нового «правительства перемен» отночения между Римом и Парижем ухудшаются с каждым месяцем. В числе противоречий-разные взгляды на политику Европейского союза в Африке, разрешение миграчионного кризиса и проблему распределения беженцев, экономическую политику стран ЕС. Однако самые фундаментальные расхождения касаются вопроса будущего европейской интеграции. В статье рассматривается суть разногласий между Италией и Франичией, и делаются выводы о тех рисках, которые этот конфликт может повлечь для развития Евросоюза.
\end{abstract}

Ключевье слова: Италия, Франция, «Движение пять звезд», Луиджи ди Майо, Эммануэль Макрон, интеграчия, Европейский союз, Ливия, Африка, мигращия, суверенитет.

С приходом к власти в Италии нового «правительства перемен» отношения между Римом и Парижем ухудшаются с каждым месяцем. В основе противоречий между двумя государствами - основателями Европейского союза - разные взгляды на политику ЕС в Африке, проблему распределения беженцев, экономическую политику стран ЕС и, пожалуй, самые фундаментальные разногласия - по вопросу будущего европейской интеграции. Однако если некоторые из этих проблем, как, например, миграционный кризис и дискуссия вокруг будущего Евросоюза, являются относительно новым фактором отношения двух стран, то проблемы конкуренции в Африке и противоречия по экономическим вопросам давно уже стали камнем преткновения для Парижа и Рима. Однако ни Рим, ни Париж не демонстрируют готовности к сглаживанию противоречий, а всё чаще публично критично высказываются в адрес друг друга, используя критику как инструмент внутриполитической борьбы и влияния на дискуссию внутри Союза. Для ЕС, изрядно измученного затяжными переговорами вокруг брекзита, ростом популизма и недисциплинированностью ряда стран Восточной Европы, публичный конфликт двух государств-основателей становится ещё одним фактором неопределённости будущего европейской интеграции, к тому же негативно влияющим на образ Союза на внешнеполитической арене.

20 января 2019 г. вице-премьер коалиционного правительства Л. ди Майо заявил, что Франция «печатает деньги для 14 стран Африки и тем самым препятствует их развитию и способствует тому, что потоки беженцев направляются в Европейский союз» ${ }^{1}$. Впоследствии он призвал «деколонизировать Африку» и подчеркнул, что ЕС, «если у него достаточно смелости, должен взять на себя ответственность заняться этой темой». Следом за ним другой ви-

\footnotetext{
(C) Алексеенква Елена Сергеевна - кандидат политических наук, старший научный сотрудник Отдела Черноморско-Средиземноморских исследований ИЕ РАН Адрес: 125009, Россия, Москва, ул. Моховая, д. 11, стр. 3. E-mail: elena-alekseenkova@yandex.ru.
}

DOI: http://dx.doi.org/10.15211/vestnikieran120193642

* Краткая версия статьи впервые опубликована на сайте РСМД 23.01.2019. URL: http://russiancouncil.ru/analyticsand-comments/analytics/italiya-i-frantsiya-esli-drug-okazalsya-vdrug-ili-ne-vdrug/

${ }^{1}$ Migranti, Di Maio: bisogna decolonizzare l'Africa. L'ambasciatrice d'Italia convocata a Parigi. ANSA.it. 22.01.2019. URL: https://www.ansa.it/sito/notizie/mondo/europa/2019/01/21/ambasciatore-italia-convocato-a-parigi_2fcb028e8c65-4478-a025-4aa053f80a1c.html (дата обращения 22.01.2019). 
це-премьер М. Сальвини заявил, что «Франция - среди тех, кто крадёт богатства Африки». В ответ на это в МИД Франции вызвали для объяснений посла Италии в Париже Т. Кастальдо, которая только подлила масла в огонь, сказав, что «если бы Франция не обогащалась за счёт африканских колоний, которых она делает ещё более бедными, она была бы пятнадцатой экономикой мира, а вовсе не одной из первых, как сейчас» ${ }^{1}$.

7 февраля Франция пошла на серьёзный дипломатический шаг - отозвала посла из Рима, объяснив это тем, что Франция в течение нескольких месяцев остаётся объектом «беспочвенных атак» со стороны итальянских властей. В последний раз процедура отзыва посла в отношениях двух стран была совершена в 1940 г., когда фашистская Италия вступила в войну на стороне Германии против Франции и Великобритании. В этот раз «последней каплей» стала встреча вице-премьера Италии Луиджи Ди Майо с лидерами французского движения «жёлтых жилетов», продолжающих протесты против политики французских властей.

Разразившийся скандал многие сочли проявлением итальянской внутриполитической борьбы. Большинство французских и итальянских СМИ действительно справедливо отмечают, что для Л. ди Майо французская карта является одной из попыток восстановления падающего рейтинга «Движения пяти звезд». И это, безусловно, так, поскольку лидер «Движения» заметно проигрывает по популярности и главе «Лиги» М. Сальвини, и председателю правительства Дж. Конте. Кроме того, уже весной 2019 г. состоятся выборы в Европарламент и все партии заметно оживились, вступив в этап предвыборной борьбы. Однако эта попытка Л. ди Майо была бы заведомо обречена на провал, если бы отношения двух стран действительно не ухудшались на протяжении уже почти десятка лет, и в итальянском общественном сознании Франция не приобретала постепенно образа главного врага внутри Европейского союза. По последним опросам ${ }^{2}, 38 \%$ населения Италии считают Францию наиболее враждебной Ита-лии внутри ЕС, и это больше, чем «антирейтинг» любой другой страны ЕС. Что же омрачает отношения двух государств - основателей Евросоюза и могут ли эти противоречия быть фак-тором риска для всего ЕС?

\section{Старые обиды: бомбардировки Ливии и экономический диктат}

Конфликт стал новым одним звеном в длинной цепи итало-французского противостояния, начавшегося ещё во времена Н. Саркози и С. Берлускони. Тогда, в далёком 2011 г. итальянский премьер-министр был в ярости от того, что французский президент в инициативном порядке начал бомбардировки Ливии, едва дождавшись одобрения других глав государств ЕС. М. Каддафи был близким другом С. Берлускони, значимым акционером итальянской «Finmeccanica», банка Unicredit, купил долю итальянской «Eni» и даже одно время владел клубом «Ювентус». Италия стала крупнейшим покупателем ливийской нефти и первым внешнеторговым партнёром Ливии. Каддафи помогал сдерживать потоки мигрантов из Ливии в Италию. Взамен Берлускони приложил огромные усилия к тому, чтобы сделать отказавшегося от поддержки терроризма и ядерного оружия бывшего «бешеного пса Ближнего Востока» М. Каддафи «рукопожатным» в США и странах Европы. У «Eni» и «Finmeccanica» были серьёзные проекты в Ливии в сфере энергетики, инфраструктуры и машиностроения. Однако уже тогда с ними конкурировали французские «Dassault» и «Total». A с началом бомбардировок и последовавших за ними свержения Каддафи и гражданской войной в Ливии, Италии стало гораздо сложнее отстаивать свои экономические интересы, а потоки мигрантов, высаживаю-

\footnotetext{
${ }^{1}$ Там же.

${ }^{2}$ Sondaggio ISPI 2018. Gli italiani e la politica internazionale. Istituto per gli studi di polica internazionale. 24.12.2018. URL: https://www.ispionline.it/it/pubblicazione/gli-italiani-e-la-politica-internazionale-21847 (дата обращения
} 21.01.2019). 
щихся на итальянских берегах, возросли многократно.

В том же 2011 г. обострилось противостояние Италии и Франции по экономическим вопросам. В тот период Италия переживала острую фазу кризиса суверенного долга, спровоцированную ситуацией в Греции. Спред достиг 500 пунктов ${ }^{1}$, и ЕЦБ срочно скупал итальянские государственные облигации, чтобы спасти страну от банкротства. Именно тогда дуумвират Франции и Германии в лице Н. Саркози и А. Меркель оказал беспрецедентное давление на С. Берлускони с тем, чтобы в стране были введены меры жёсткой экономии, а президент ЕЦБ француз Ж.-К. Трише направил правительству Италии официальное письмо с требованием провести ряд экономических реформ. С тех пор в итальянском общественном сознании прочно укоренился комплекс страны с «ущемленным суверенитетом», находящейся во внешнем управлении Брюсселя.

\section{Новые реалии: конкуренты в Африке, оппоненты в вопросах миграции и будущего Европейского союза}

В сегодняшних условиях Италия и Франция по-прежнему пытаются конкурировать в Ливии и ведут «войну конференций». В 2012 г. Италия сделала ставку на новое правительство Ливии в Триполи. Правительство национального единства во главе с Ф. Сараджем было сформировано в декабре 2015 г. при активном содействии Рима. Было заключено новое соглашение в сфере миграции. Тем не менее, сегодня итальянскому руководству вполне очевидно, что официальное правительство Ливии с трудом способно гарантировать защиту итальянских экономических интересов, не говоря уже о контроле над потоками мигрантов. Итальянское руководство осознаёт, что требуется системное решение ливийской проблемы, без которого не может быть решён и миграционный вопрос ${ }^{2}$ С этой целью уже осенью 2018 г. Рим начал взаимодействовать и с другими ливийскими акторами, такими как маршал Х. Хавтар ${ }^{3}$. Франция же, напротив, официально поддержав Правительство национального единства, довольно давно и тесно взаимодействует с Х. Хавтаром. Однако главная задача и Франции и Италии сегодня - это проявить себя как важного регионального игрока, оказывая посредничество в процессе ливийского примирения, и, безусловно, получить соответствующие экономические дивиденды. С целью предстать в виде главной переговорной площадки сначала Франция, а затем Италия созвали статусные международные конференции по Ливии: весной - в Париже, в ноябре 2018 г. - в Палермо.

Однако Франция не только конкурирует с Италией в Ливии, но и пытается взять на себя лидерство в формировании внешней политики Европейского союза в Африке. Так, еще в сентябре 2017 г. в речи «Инициатива для Европы» Э. Макрон заявил о том, что Африка и Средиземноморье - важнейшие приоритеты внешней политики Европейского союза, поскольку это регион ближайшего соседства, который формирует самые серьезные вызовы для EC. Поэтому ЕС нуждается в хорошо проработанной африканской стратегии, и, конечно же, Франция готова сыграть одну из главных ролей в формировании и осуществлении такой стратегии. В данном контексте обвинения Л. ди Майо выглядят как сознательный «подрыв авторитета» Франции как возможного лидера африканской политики Евросоюза.

Заявлением об африканской валюте Л. ди Майо способствует разжиганию давних противоречий в отношениях между Францией и её бывшими колониями. Курс франка КФА из-

\footnotetext{
${ }_{1}^{1}$ Спред - разница в уровне доходности долгосрочных казначейских облигаций между Германией и Италией.

${ }^{2}$ La Libia tra conflitto e migranti: ripensare il ruolo delle milizie. ISPI. 18.07.2018. URL: https://www.ispionline.it/it/ pubblicazione/la-libia-tra-conflitto-e-migranti-ripensare-il-ruolo-delle-milizie-21012.

${ }^{3}$ Libia, il generale Haftar gioca a nascondino con Conte, ma alla Conferenza «sarà presente». TNews. 12.11.2018. URL: https://notizie.tiscali.it/esteri/articoli/haftar-gioca-con-conte/ (дата обращения 27.01.2019).
} 
начально был жёстко привязан к курсу французского франка, с введением евро он получил фиксированное соотношение с евро. В обмен на гарантию конвертируемости франка КФА со стороны Франции страны-участницы валютного союза согласились поместить $65 \%$ своих валютных резервов на специальный счёт в Казначействе Франции. Также бывшей метрополии было предоставлено право вето в отношении денежной политики стран Зоны франка в случае овердрафта счёта. В ряде стран, использующих франк КФА, действительно присутствует мнение, что посредством франка КФА продолжает поддерживаться французская неоколониальная система, которая эксплуатирует ресурсы стран региона, замедляет рост и вынуждает молодежь эмигрировать, рискуя жизнью. Однако сторонники франка КФА считают его фактором стабильности, который помог экономикам 14 африканских стран не страдать от высокой инфляции и параллельных рынков, как это произошло, например, в Зимбабве 1 .

Таким образом, усилия на ливийском направлении и попытка подрыва авторитета Франции в бывших колониях намекают на то, что Италия готова оспаривать французское лидерство в формировании внешней политики ЕС в Африке.

Помимо этого, Италия и Франция уже не раз публично упрекали друг друга в несоблюдении своих обязательств в сфере приёма беженцев. Накануне июньского саммита ЕС 2018 г., когда Италия отказывалась принимать в свой порт судно с беженцами «Аквариус», Э. Макрон обвинял Рим в «цинизме и безответственности», а Италия, в свою очередь, упрекала французские власти в систематическом отказе принимать тех мигрантов, которые прибыли в Италию, но по соответствующей квоте должны быть переправлены во Францию.

В марте 2018 г. отношения Италии и Франции обострились из-за конфликта вокруг действий французской полиции в лагере беженцев в итальянском г. Бардонеккьо. Тогда французский посол был вызван для объяснений в МИД Италии, а первые лица страны обвиняли французские власти в нарушении государственного суверенитета Италии ${ }^{2}$.

В Риме весьма разочарованы отсутствием конкретных шагов в реализации договорённостей, достигнутых на июньском саммите Европейского союза 2018 г. в сфере миграции. Правительство скептически относится к способности ЕС коллективно справиться с притоком беженцев и уже активно действует на этом направлении в одиночку. В частности, осенью 2018 г. был принят нашумевший «закон о безопасности» ${ }^{3}$, в котором Италия суверенно определила правила содержания мигрантов, запросивших статус беженца, и правила его предоставления. Кроме того, министр внутренних дел Италии М. Сальвини объявил итальянские по́рты закрытыми для судов НПО, спасающих мигрантов в море, считая их контрабандистами. По мнению итальянского руководства, необходимо сосредоточиться на помощи мигрантам на ливийских берегах, коль скоро страны Европейского союза не могут договориться о справедливом распределении беженцев и создании эффективно работающей системы контроля границ ЕС. В частности, под вопросом стоит продление операции «София», к пересмотру условий которой с лета 2018 г. призывает Италия, играющая ключевую роль в реализации мер спасания.

В качестве ещё одного фактора напряжённости стоит отметить также публичную поддержку со стороны Л. Ди Майо и М. Сальвини движения «жёлтых жилетов» во Франции в

\footnotetext{
${ }^{1}$ В 2008 г. из-за гиперинфляции началось стремительное формирование «чёрного рынка», где расчёты осуществлялись в долларах США, а не в официальной валюте, которой являлся доллар Зимбабве.

2 Migranti, blitz a Bardonecchia. La Farnesina convoca l'ambasciatore e smentisce Parigi: «Regole violate, rapporti a rischio». 31 Marzo 2018. URL: https://torino.repubblica.it/cronaca/2018/03/31/news/coro_di_proteste_contro_1_irru zione_dei_francesi_non_siamo_la_toilette_di_macron-192649605/ (дата обращения: 23.01.2019).

${ }^{3}$ DECRETO-LEGGE 4 ottobre 2018, n. 113. Gazzetta Ufficiale. URL: http://www.gazzettaufficiale.it/eli/id/2018/10/ 04/18G00140/sg (дата обращения: 23.01.2019).
} 
декабре 2018 - феврале 2019 гг. ${ }^{1}$ В этот раз уже Франция усмотрела в публичных выступлениях итальянских официальных лиц нарушение национального суверенитета и вмешательство во внутренние дела государства.

Потенциал нового конфликта двух государств - основателей Евросоюза несут в себе выборы в Европарламент в мае 2019 г. В октябре 2018 г. М. Сальвини и лидер «Национального объединения» Франции М. Ле Пен объявили об объединении своих усилий на общеевропейских выборах. «Мы с Маттео Сальвини не боремся с Европой, мы боремся с Европейским союзом, как с тоталитарной системой, и наша борьба нацелена на спасение настоящей Европы», - заявила Ле Пен ${ }^{2}$. Безусловно, это один из главных раздражителей в отношениях Рима и Парижа. В то время как Э. Макрон призывает к новому этапу интеграции ЕС, итальянское правительство, по сути, открыто поддерживает его главного оппонента и конкурента. В таких условиях перспективы сотрудничества Италии и Франции в деле строительства новой «единой Европы» вызывают большие сомнения.

\section{Разные образы будущего}

Глубинная причина конфликта Италии и Франции, однако, не в Африке, не в миграции и не в отсутствии дипломатической вежливости, а в разном видении будущего Европейского союза и положения своих стран внутри ЕС. Франция открыто говорит о лидерском тандеме с Германией в деле спасения и укрепления европейской интеграции, в то время как в Риме «лидерские» амбиции Парижа и Берлина воспринимаются крайне негативно как стремление «навязать» своё видение будущего развития Союза. В Риме опасаются, что в такой «единой Европе» не остается места для Италии, которая декларирует стремление стать более активным актором на международной арене. При этом, если для Э. Макрона существует только «суверенная Европа», а понятие «совранизм» (т.е. защита приоритета национального суверенитета над наднациональным) имеет исключительно негативный окрас ${ }^{3}$, то для итальянских руководителей «национальный суверенитет» - это фундамент их политической поддержки и главный элемент политической программы. И наверняка в Париже осознают тот факт, что популярность нового «спасителя единой Европы» Э. Макрона в самой Франции достигла минимума с момента выборов, а вот рейтинг сторонника «национального суверенитета», популиста М. Сальвини продолжает расти.

Итальянское «правительство перемен», апеллируя к суверенитету народа Италии в принятии ключевых политических и экономических решений, по сути, ставит под вопрос не только дальнейшие шаги в сторону углубления европейской интеграции, но призывает к пересмотру уже функционирующих институтов, норм и правил Евросоюза, и самое важное - к пересмотру границы между национальным и наднациональным. Ключевой вопрос 2019 г. как покажут себя французские «интеграционисты» и итальянские «совранисты» не только на выборах в Европарламент, но и внутри своих стран. Это будет зависеть от того, удастся ли Э. Макрону восстановить утраченную поддержку, реализуя ряд непопулярных реформ, а итальянскому «правительству перемен» - удержать её, проводя в жизнь те решения, которые поддержал итальянский народ. Кроме того, важное значение для всего Европейского союза бу-

\footnotetext{
${ }^{1}$ Francia-Italia, dai gilet gialli all'Africa: M5s all'assalto di Macron. Affaritaliani.it. 21.01.2019. URL: http://www.affa ritaliani.it/affari-europei/francia-italia-rapporti-ai-minimi-termini-m5s-assalto-di-macron-582915.html (дата обращения 23.01.2019).

2 Дружба против ЕС: Сальвини и Ле Пен решили объединиться. Euronews.com. URL: https://ru.euronews.com/ 2018/10/08/ru-salvini-le-pen-presser (дата обращения: 23.01.2019).

${ }^{3}$ Merkel e Macron, i principi feriti che difendono il castello d'Europa. La Reppublica. 18.11.2018. URL: https://rep.rep ubblica.it/pwa/editoriale/2018/11/18/news/merkel_e_macron_i_principi_feriti_che_difendono_il_castello_d_europa-21 2027201/?ref=RHPPTP-BH-I0-C12-P1-S1.4-T1 (дата обращения 21.01.2019).
} 
дет иметь баланс «интеграционистов» и «совранистов» в политических институтах ЕС и в национальных политических элитах: уже сейчас можно наблюдать, как фронт евроскептиков начинает расширяться и приобретать коалиционный характер. Помимо союза с Ле Пен, римские власти выстраивают диалог с польской партией «Право и справедливость» и имеют тесные контакты с венгерским лидером В. Орбаном. Между тем пока не вполне понятно, каков баланс национального и наднационального в понимании новых европейских «совранистов». Есть ли у них какое-то общее видение будущего ЕС и пределов свободы национальных государств?

Конфликт Рима с Брюсселем по вопросу итальянского бюджета на 2019 г., а также расходящиеся позиции стран Евросоюза по вопросам финансовой дисциплины позволяют сделать вывод, что требования большей самостоятельности национальных правительств в финансовой сфере будут звучать и далее. Понятно также, что в миграционной сфере продолжится тенденция на «суверенизацию» государств. В сфере общей внешней политики и политики безопасности (в частности, в регионе Ближнего Востока и в Африке) странам Европейского союза вряд ли удастся сформировать единое видение стратегий и подходов в ближайшем будущем. Фундаментальные противоречия ключевых государств ЕС свидетельствуют о глубоком кризисе доверия и препятствуют формированию солидарности внутри Союза. Безусловно, внешние факторы и риски нестабильности (прежде всего, поведение США, России, Китая) могут способствовать повышению уровня доверия внутри Евросоюза. Это уже заметно на примере единогласного продления санкций в отношении России или приведения в действия «Блокирующего статута» в связи с восстановлением США санкций в отношении Ирана. Однако рассчитывать на сплачивающую роль внешних угроз весьма опасно - ведь внешние игроки могут использовать имеющиеся разногласия стран ЕС в своих целях, тем самым усугубив их. Таким образом, очевидно, что преодоление кризисных явлений внутри ЕС возможно только в том случае, если хотя бы в «ядре» Союза будет найден новый баланс между национальным и наднациональным суверенитетом и появятся новые внутренние факторы, способствующие формированию «доверия».

\section{Список литературы}

Дружба против EC: Сальвини и Ле Пен решили объединиться. Euronews.com. URL: https://ru.euronews.com/2018/10/08/ru-salvini-le-pen-presser.

\section{References}

DECRETO-LEGGE 4 ottobre 2018, n. 113. Gazzetta Ufficiale. URL: http://www.gazzettauffici ale.it/eli/id/2018/10/04/18G00140/sg.

Francia-Italia, dai gilet gialli all'Africa: M5s all'assalto di Macron. Affaritaliani.it. 21.01.2019. URL: http://www.affaritaliani.it/affari-europei/francia-italia-rapporti-ai-minimi-termini-m5s-assalto -di-macron-582915.html.

La Libia tra conflitto e migranti: ripensare il ruolo delle milizie. ISPI. 18.07.2018. URL: https:// www.ispionline.it/it/pubblicazione/la-libia-tra-conflitto-e-migranti-ripensare-il-ruolo-delle-milizie21012.

Libia, il generale Haftar gioca a nascondino con Conte, ma alla Conferenza «sarà presente». TNews. 12.11.2018. URL: https://notizie.tiscali.it/esteri/articoli/haftar-gioca-con-conte/.

Merkel e Macron, i principi feriti che difendono il castello d'Europa. La Reppublica. 18.11.2018. URL: https://rep.repubblica.it/pwa/editoriale/2018/11/18/news/merkel_e_macron_i_principi_feriti_ 
che_difendono_il_castello_d_europa-212027201/?ref=RHPPTP-BH-I0-C12-P1-S1.4-T1.

Migranti, blitz a Bardonecchia. La Farnesina convoca l'ambasciatore e smentisce Parigi: «Regole violate, rapporti a rischio». 31 Marzo 2018. URL: https://torino.repubblica.it/cronaca/2018/03/31/new s/coro_di_proteste_contro_1_irruzione_dei_francesi_non_siamo_la_toilette_di_macron-192649605/

Migranti, Di Maio: bisogna decolonizzare l'Africa. L'ambasciatrice d'Italia convocata a Parigi. ANSA.it. 22.01.2019. URL: https://www.ansa.it/sito/notizie/mondo/europa/2019/01/21/ambasciato re-italia-convocato-a-parigi_2fcb028e-8c65-4478-a025-4aa053f80a1c.html.

Sondaggio ISPI 2018. Gli italiani e la politica internazionale. Istituto per gli studi di polica internazionale. 24.12.2018. URL: https://www.ispionline.it/it/pubblicazione/gli-italiani-e-la-politica-in ternazionale-21847.

\section{Italy and France: conflicting over the future of the $\mathrm{EU}$}

Author. Elena Alekseenkova, Candidate of Sciences (Politics), Senior Research Associate, Department of Black and Mediterranean Sea Studies, Institute of Europe, Russian Academy of Sciences. Address: 11-3, Mokhovaya str., Moscow, Russia, 125009. E-mail: elenaalekseenkova@yandex.ru.

Abstract. With the coming to power of a new «government of change» in Italy, relations between Rome and Paris are constantly deteriorating. Fundamental contradictions are caused by different views on EU policies in Africa, the resolution of the migration crisis and refugees relocation, EU economic policies and, perhaps, the most fundamental differences on the future of European integration. The paper discusses the essence of disagreements between Italy and France and draws conclusions about the risks that this conflict may entail for the development of the European Union.

Key words: Italy, France, «Five Star Movement», Luigi di Maio, Emmanuel Macron, European integration, Libya, Africa, migration, sovereignty.

DOI: http://dx.doi.org/10.15211/vestnikieran120193642 